\title{
Relationships between Biochemical Criteria, Volatile Compounds, and Sensory Profiles of Ten Apricot Clones at Commercial and Consumption Ripening Stages
}

\author{
Jamal Ayour $\mathbb{B}^{\mathbb{D}},{ }^{1}$ Mohamed Benichou, ${ }^{1}$ Abderrahim Alahyane ${ }^{\mathbb{D}},{ }^{1}$ and Hasnaâ Harrak ${ }^{2}$ \\ ${ }^{1}$ Food Sciences Laboratory, Faculty of Sciences Semlalia, Cadi Ayyad University, M-40090 Marrakesh, Morocco \\ ${ }^{2}$ Laboratory of Agri-Food Technology and Quality, Regional Centre for Agricultural Research in Marrakesh, \\ National Institute for Agricultural Research (INRA), P.O. Box 533, Marrakesh 40000, Morocco
}

Correspondence should be addressed to Jamal Ayour; jamal.ayour@ced.uca.ac.ma

Received 11 July 2020; Revised 21 August 2020; Accepted 12 September 2020; Published 27 September 2020

Academic Editor: Fabio Napolitano

Copyright (C) 2020 Jamal Ayour et al. This is an open access article distributed under the Creative Commons Attribution License, which permits unrestricted use, distribution, and reproduction in any medium, provided the original work is properly cited.

In association with a desirable balance of sugars and organic acids, volatile compounds contribute to the important sensory attributes of apricots. This study assessed the biochemical, aromatic, and sensory qualities of ten Moroccan apricot clones at two maturity stages (M1: commercial stage and M2: consumption stage). Sucrose (1.84-7.09 g/100 g of fresh weight (FW)) and citric acid (0.56-2.25 g/100 g FW) were the main sugar and organic acid in fresh apricots, respectively. The principal identified volatile compounds classes were aldehydes, alcohols, and acetates. The major apricot volatile compounds, hexanal $(15.43-696.35 \mu \mathrm{g} / \mathrm{kg}$ FW), 2-hexenal $(9.04-404.72 \mu \mathrm{g} / \mathrm{kg} \mathrm{FW}), \beta$-linalool $(8.49-880.50 \mu \mathrm{g} / \mathrm{kg} \mathrm{FW})$, and 1-hexanol $(3.35-86.00 \mu \mathrm{g} / \mathrm{kg} \mathrm{FW})$, were previously reported to be major contributors to apricot flavor. Multivariate analysis revealed a significant impact of the ripening stage on the perception of sensory quality related to biochemical parameters. At the commercial stage, apricots were more firm and acidic, characterized by herbaceous odor and high citric acid level, while at the consumption stage, fruits were sweeter, having high reducing sugars (glucose and fructose) contents, and characterized by floral, fruity, and apricot flavors. Among suggested cultivars as suitable for consumption as fruits, red clones ("Cg 2" and "Mans 15") and orange clones ("Marouch 16," "Ab 5," "Rtil 4" and "Marouch 4") showed very interesting sensory attributes, aroma, and sugar-acid balance, expressing a good overall quality of apricot fruits.

\section{Introduction}

Apricot was considered in the Mediterranean's countries as one of the most delicious temperate fruits, characterized by strong fruity aroma and a good taste based on high soluble sugars and reasonable organic acids that are considered as major determinants of the quality of the fruits [1]. Research programs were, thus, focused on improving the flavor of apricots regarding important roles played by the organic acids and soluble sugars in fruit $[1,2]$. A better taste for apricot has been associated with an increase in the soluble sugar content [3], with sucrose as the main soluble sugar in the fruit [2].

In the case of fleshy fruit such as apricot fruit, alongside agronomic aspects (regularity of yields, vigor of trees, resistance or tolerance to diseases, size, and color of fruit), internal fruit quality and appreciation of consumers are criteria taken into account earlier in the selection process. Therefore, the establishment of sensory profiles by panelists is a powerful tool for characterization of the different genotypes of apricot [4]. It allows good, relevant, and simple information by comparison to the instrumental methods of measuring firmness, sugar content, and acidity [5] and also allows evaluating other characteristics such as juiciness, flavor, and other taste attributes. Moreover, sensory ratings of fruit by panelists and biochemical measurements of fruit properties are useful methods in the evaluation of fruit quality $[2,6]$.

Previous studies have reported that sugars and organic acids contents play an important role in fruit taste through 
the sugar/acid ratio [7-9]. Moreover, apricot quality consists of a balance of sugar and acidity, as well as a strong apricot aroma $[10,11]$. So, the knowledge of the qualitative and quantitative compositions of acids and sugars in apricot fruits may prove to be a powerful tool in evaluating fruit maturity and quality [12].

Consumers' interest focuses on the flavor and aroma of apricot. The soluble sugars and organic acids were the most appreciable quality attributes of apricot [13], and they are directly related to the taste of fruit. Sweetness is mostly attributable to mono- and disaccharides, while sourness is linked with organic acids and $\mathrm{pH}$. Sweetness and juiciness are also relevant quality characteristics of apricots [14]. Apricot is also very much appreciated for its pleasant and delicious aroma [15], which contributes to its organoleptic quality. These characteristics are strongly related to the cultivar and ripening stage [16]. Aroma is elicited by volatile compounds which originate from different metabolic pathways such as the fatty acid metabolism, amino acid metabolism, and carbohydrate metabolism [17]. Different proportions of the volatile components determine the overall aroma properties. Aroma also has a powerful impact on fruit quality and with the volatile components being a definitive factor species quality [14]. Moreover, the aroma of apricot is a major quality component that distinguishes the fruit of apricot from other fruits of the same family such as plums and their interspecific hybrids because it is associated with a large number of distinct volatile compounds, such as terpenes, alcohols, lactones, esters, and other C6 compounds (aldehydes and ketones) [14, 18, 19]. In addition, a recent study has also confirmed the importance of the aroma in the quality determination of apricot quality by the consumer, generally showing a direct impact on consumer acceptance [15].

Despite a large number of studies on the characterization of apricot quality, in particular on sugar and organic acid contents [3, 20-22] and volatiles compounds of fruits $[18,19,23-25]$, no enough studies have been made to determine if an association exists between sensory criteria, volatile compounds, and sugar-acid balance, especially when they are related to ripening and genotype impacts. This association may represent an important quality parameter of apricot fruits.

To the best of our knowledge, this study is the first which provides data about the biochemical and aromatic compounds composition and sensory profile of Moroccan apricots during fruit ripening. The objectives of this work were as follows: (1) to describe the fruits sensory traits of ten Moroccan apricot clones and to determine their volatile compounds; (2) to analyse some quality criteria, namely, soluble sugars and organic acids contents, and their influence on apricot taste; and (3) to evaluate genotype and ripening stage impacts on apricot sensory and biochemical criteria.

\section{Materials and Methods}

2.1. Plant Material. The studied plant material included 10 apricot clones named "Boum A2," "Agdez LG1," "Marouch
4," “Ab 5," "Marouch 16," "Rtil 4," "Clone C," "Mans 15," "Agdez C2," and "Cg 2"(Supplementary table 1). These clones were collected from apricot collection in the Saâda experimental field of the Regional Center for Agricultural Research in Marrakesh, National Institute for Agricultural Research, INRA, Morocco $\left(30^{\circ} 21^{\prime} 8.4^{\prime \prime} \mathrm{N}, 9^{\circ} 30^{\prime} 29^{\prime \prime} \mathrm{W}\right)$.

The experimental orchard has 184 trees gathered in a collection for a surface of 2 ha. It was planted in 1995 and used for drip irrigation. The trees were planted at a density of $4.5 \times 2 \mathrm{~m}$, arranged in 7 columns $\times 30$ rows and managed with standard cultivation practices:

(i) Organic manure of $40 \mathrm{~T} / \mathrm{ha}$

(ii) Major elements (NPK) equivalent to the annual needs (estimated at: N: 100-150 U/ha, P205: 80-100 U/ha; K20: $150 \mathrm{U} / \mathrm{ha})$

(iii) An average size and thinning to adjust the load to the growth potential of the tree

The harvest was started in such a way as to optimize the compromise between optimal maturity favoring the expression of the taste quality of the fruits and the fruits aptitude for preservation in postharvest circuits. The flowering of the apricot tree is between February and March for a harvest between April and May for early cultivars and between May and June for other varieties.

All the clones were harvested at two different maturity stages (M1: commercially ripe and M2: consumption ripe) (Figure 1). For each clone, the ripening stage was based on assessing manually fruit firmness and surface color. The fruit was considered commercially ripe when it reached full size and an intense color (pale-yellow, orange, or red depending on genotype), but the apricot is still firm enough to withstand handling, transport, and storage. At the consumption stage, the fruit is soft and can easily be detached from the tree. It is the fruit dedicated to the local market and for almost immediate consumption (ready to be eaten). After harvest, apricot samples were placed into fruit crates and transferred to the laboratory for the analysis.

2.2. Sensory Analyses. Quantitative descriptive sensory analysis as described in the standard ISO 11035-2009 was performed. The analyses were carried out in the sensory analysis room of the Laboratory of Food Technology and Quality in the INRA, Marrakesh, established in accordance with the general guidelines for premises of sensory evaluation: ISO 8589-2007. The panel training procedure, including the sensory attributes and the scales of measures, was carried out according to a previous study [26]. The sensory profile consists of a list of 17 attributes (Table 1) referring to the appearance, smell, flavor, and texture of the fruits, which were assessed on a linear scale of intensity ranging from 0 to $10 \quad(0=$ extremely low intensity, $5=$ medium intensity, and $10=$ extremely high intensity).

The sensory evaluations were performed according to the published apricot attributes [12, 27, 28]. During each session, two clones were evaluated by sensory panelists according to the 17 attributes and the predefined methods. The evaluation was carried out on 5 fruits per stage of 


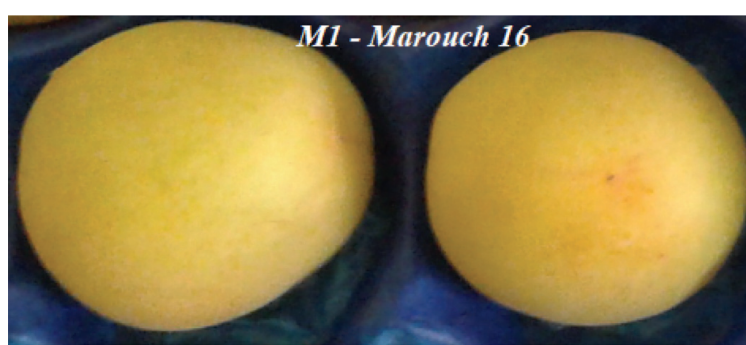

(a)

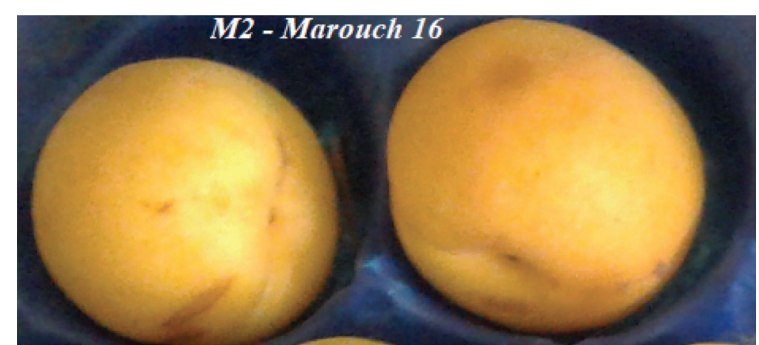

(b)

Figure 1: Example of "Marouch 16" clone at two maturity stages (M1: commercially ripe and M2: consumption ripe). (a) M1-Marouch 16. (b) M2-Marouch 16.

TABLE 1: Sensory profile of apricot clones evaluated by panelists.

\begin{tabular}{lc}
\hline Sensory criteria & Attribute \\
\hline \multirow{3}{*}{ Color } & Unblush color \\
& Blush color \\
& Flesh color \\
\hline & Hardness \\
Texture & Skin hardness \\
& Flesh cohesion \\
& Crunchy \\
& Juiciness \\
Odor/flavor & Herbaceous odor \\
& Apricot flavor \\
& Fruity flavor \\
& Floral flavor \\
\hline \multirow{2}{*}{ Taste } & Sourness \\
& Sweetness \\
& Astringency \\
& Bitterness \\
\end{tabular}

maturity per clone, and the order of presentation of the samples was the same for the entire panel (8 panelists).

2.3. Dosage of Soluble Sugars and Organic Acids. Two replicates of 10 fruits for each maturity stage per clone were selected, ground, and kept at $-80^{\circ} \mathrm{C}$ for biochemical analysis, especially soluble sugars, organic acids, and volatile compounds. The dosage was made on frozen crushed samples. For each replicate, $10 \mathrm{ml}$ of distilled water is added to $2.5 \mathrm{~g}$ of frozen ground apricot. The preparation is homogenized and centrifuged for $10 \mathrm{~min}$, at $4^{\circ} \mathrm{C}$ at $9000 \mathrm{~g}$ (Hettich 320R, Bäch, Switzerland). The supernatant is recovered after filtration on stamen. The supernatant must be diluted in order to correspond to the concentration range of the enzymatic kits.

Sugars (glucose, fructose, and sucrose) and organic acids (malic and citric acids) were quantified using an enzymatic method with kits for food analysis (R-Biopharm AG, Darmstad, Germany), especially specific enzymatic test kits for L-malic acid, citric acid, glucose/fructose, and sucrose. Results are expressed in $\mathrm{g} / \mathrm{kg}$ of fresh weight for sugars and acids. These measurements were performed with a SAFAS FLX-Xenius XM spectrofluorimeter (SAFAS, Monaco) equipped with a SAFAS automatic injection device.

\subsection{Dosage of Volatile Compounds}

2.4.1. Volatile Sample Preparation and HS-SPME Conditions. Volatile compounds were prepared by HS-SPME (Head space-Solid phase microextraction) using the previous method [19]. For each replicate, $5 \mathrm{~g}$ of frozen ground apricot was placed into a $20 \mathrm{~mL}$ headspace vial, sealed with a septum and an aluminum cap. $5 \mu \mathrm{l}$ of 4 -nonanol solution at $0.22 \mu \mathrm{g} /$ $\mu \mathrm{l}$ was also added as an internal standard.

The SPME technique in the head space mode was used for the extraction of volatile compounds. The sampling was performed in an automated mode using the autosampler (Triplus RSH autosampler, Thermo Scientific, USA) equipped with the $75 \mu \mathrm{m}$ Carboxen/Polydimethylsiloxane (CAR/PDMS) fiber from Supelco (Bellefonte, PA, USA). The fiber was preconditioned before the analysis, according to the instructions of the manufacturer. The sample was preheated to $40^{\circ} \mathrm{C}$ for $10 \mathrm{~min}$ for equilibration, and volatile compounds were extracted by exposing the SPME fiber to the headspace of the sample vial that was maintained at the same temperature for $30 \mathrm{~min}$. The analytes were desorbed for 3 min from the fiber into the GC injector set at $250^{\circ} \mathrm{C}$ in the spilt mode $(1: 5)$.

2.4.2. GC-MS Conditions. Sample analyses were performed using a GC-MS System ISQ ${ }^{\mathrm{TM}}$ LT Single Quadrupole (Thermo Scientific, USA), equipped with a TriPlus RSH autosampler to automate SPME and a TGWAX-MS Column $(30 \mathrm{~m} * 0.25 \mathrm{~mm} * 0.5 \mu \mathrm{m})$. The mass spectrometer was operated in the electron ionization (EI) mode at the ionization voltage of $70 \mathrm{eV}$ in the mass range of $31-210 \mathrm{~m} / \mathrm{z}$ at a scan rate of $0.2 \mathrm{scan} / \mathrm{s}$, with the transfer line and ionization source temperature of $250^{\circ} \mathrm{C}$. The $\mathrm{GC}$ oven temperature program consisted of $40^{\circ} \mathrm{C}$ for $2 \mathrm{~min}$ (desorption period), $40-70^{\circ} \mathrm{C}$ at $5^{\circ} \mathrm{C} / \mathrm{min}, 70^{\circ} \mathrm{C}$ for $1 \mathrm{~min}$, and $70-230^{\circ} \mathrm{C}$ for $30 \mathrm{~min}$ at $10^{\circ} \mathrm{C} / \mathrm{min}$.

Helium was used as a carrier gas with a constant column flow rate of $1 \mathrm{ml} / \mathrm{min}$. The identification of the volatile compounds was carried out comparing mass spectral data with those of the NIST 2014 library. The Refractive Index (RI) values were also compared with those described in the literature and determined under the same conditions for matching the volatile compounds. The individual volatile compounds (identified and unidentified peaks) were 
tentatively quantified based on their peak areas relative to that of the internal standard (4-nonanol). Two analyses were performed for each sample. The results are expressed as 4nonanol equivalent in $\mu \mathrm{g} / \mathrm{kg}$ of fresh weight.

2.5. Statistical Analysis. Statistical analyses were performed using the software package XLSTAT statistical software version 2011. The data were tested for differences between the clones using the one-way analysis of variance (ANOVA). The method used to discriminate among means (multiple range tests) was Fisher's least significant difference (LSD) procedure at $95.0 \%$ confidence level. Data parameters of each apricot clone were analyzed by means of multivariate analysis employing principal component analysis (PCA) and hierarchical cluster analysis. The analytical reproducibility of the obtained data was determined as pooled standard deviations (Pooled SD). This statistical parameter was calculated for each series of replicates per variable using the sum of individual variances weighted by the individual degrees of freedom.

\section{Results and Discussion}

3.1. Sensory Profiles. The apricot sensory data for each maturity stage are presented in Tables 2 and 3. An important variability was found between sensory attributes related to clones and maturity stages. Among apricot clones, significant differences were observed between the studied variables except for hardness, crunchiness, bitterness, astringency, and sourness for the M1 stage and flesh cohesion, herbaceous odor, bitterness, astringency, and acidity persistence for the M2 stage. Christen et al. [27] have also reported that bitterness and acidity persistence not allowed differentiating significantly between apricot varieties during the sensory measurements.

The evaluation by panel experts proved that apricot clones in the M2 stage had good characteristics for fresh consumption because of the high intensities of key attributes, especially fruity flavor (9.33) and sweetness (8.67) registered for "Cg 2." Regarding both the maturity stages (M1 and M2), different patterns were found, and different attributes levels were obtained for the studied apricot clones. Indeed, the ripening had a marked impact on the sensory characteristics of apricots. The sensory scores of lightness, skin hardness, hardness, bitterness, astringency, herbaceous odor, crunchiness, sourness, and persistence were higher in the M1 stage for all apricot clones (Table 2), while those of blush color, flesh color, juiciness, sweetness, apricot flavor, fruity flavor, and floral flavor were higher in the M2 stage (Table 3).

Blush color, skin hardness, fruity flavor, and sweetness were the attributes that best explain the difference between the studied clones (Figure 1). Comparing the results of both maturity stages, it was noticed that the M2 stage was the most appropriate stage for consumption of apricots compared to the commercial stage (M1). It has been characterized with high attributes of flavors and taste. It was, then, the best stage to show the qualitative potential of the studied apricot clones. Indeed, at the M2 stage, regarding flavor notes, all studied clones showed a good apricot flavor $(>5)$. The same profile was found for fruity flavor and a little different for floral flavor (<5) for "Boum A2," "Agdez LG1," and "Marouch 4." Regarding sweetness, an evolution of this criteria with skin color has been noticed (except for "Boum A2"), knowing that red clones, especially "Cg 2" was the sweetest, followed by orange clones and pale-yellow ones. However, the opposite was observed for sourness note, knowing that the pale-yellow apricots were sourer while the "Cg 2" had low note. In addition, for all clones, the M1 stage was characterized by high levels of sourness comparing to M2.

Among the studied apricots, "Cg 2" was the most appreciated clone, followed by "Marouch 16" and "Agdez C2" (Figure 2). They were highly aromatic, very tasteful, and had a balanced level of acidity and sweetness. But, in general, sensory data proved that all apricot clones are characterized by interesting quality attributes and they are appropriate for fresh consumption. This heterogeneity of the various sensory attributes may have its explanations on the biochemical proprieties of the apricot fruit related to genotype.

3.2. Soluble Sugars and Organic Acids Contents. The multivariate analysis revealed that, for both stages of maturity, soluble sugars and organic acids of the ten apricot clones are significantly different $(p \leq 0.05)$.

The sugars and organic acids contents of the studied apricot clones are given in Figure 3. The three known soluble sugars of the apricot fruit have been quantified. The amounts of sucrose, glucose, and fructose depended on clone and the ripening stage. Sucrose was reported as a predominant soluble sugar in apricot followed by glucose and fructose $[9,12]$. Le Bourvellec et al. [29] have reported recently that sucrose was the main sugar in fresh apricots ranging from 37 to $77 \% \mathrm{FW}$ of total sugars, followed by glucose $(13-33 \% \mathrm{FW})$ and fructose $(9-39 \% \mathrm{FW})$. Fairly similar proportions were observed with the ten studied clones for sucrose (29-89\%), glucose (4-49\%), and fructose (6-22\%) depending on clones and maturity stages, the highest in sucrose content being the lowest in glucose and fructose contents. The sugar concentrations are comparable and fairly in accordance with other studies [30-33] which reported concentration ranging from 1.2 to $11.7 \mathrm{~g} / 100 \mathrm{~g}$ FW for sucrose, 0.6 to $5.46 \mathrm{~g} / 100 \mathrm{~g}$ FW for glucose, and from 0.1 to $4.42 \mathrm{~g} / 100 \mathrm{~g} \mathrm{FW}$ for fructose.

Concerning organic acids, the major ones are malic and citric acids (Figure 3), in agreement with other studies $[3,22,34-36]$. The contents were in the concentration ranges reported previously [3] (citric acid: 1.2-21.6 and malic acid: $3.5-16.7 \mathrm{~g} / \mathrm{kg}$ of FW) and on a large variability [31] (maturity stage and clones) (citric: $0.1-26.6$ and malic: $0-20.2 \mathrm{~g} / \mathrm{kg}$ of FW). The citric acid ranges were in agreement with the results found by Ayour et al. [22]. However, differences have been observed in the content of malic acid compared to this previous study [22]. This is probably due to the year impact on fruit acidity and the effect of the used method in each study (HPLC and enzymatic method).Several studies have indicated the importance of a relatively high organic acids content for a 


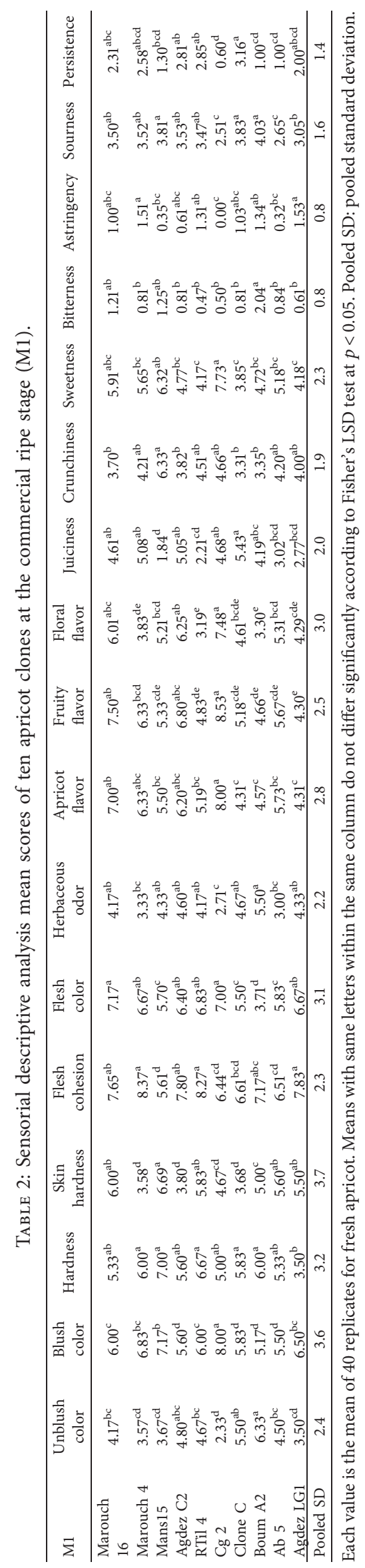




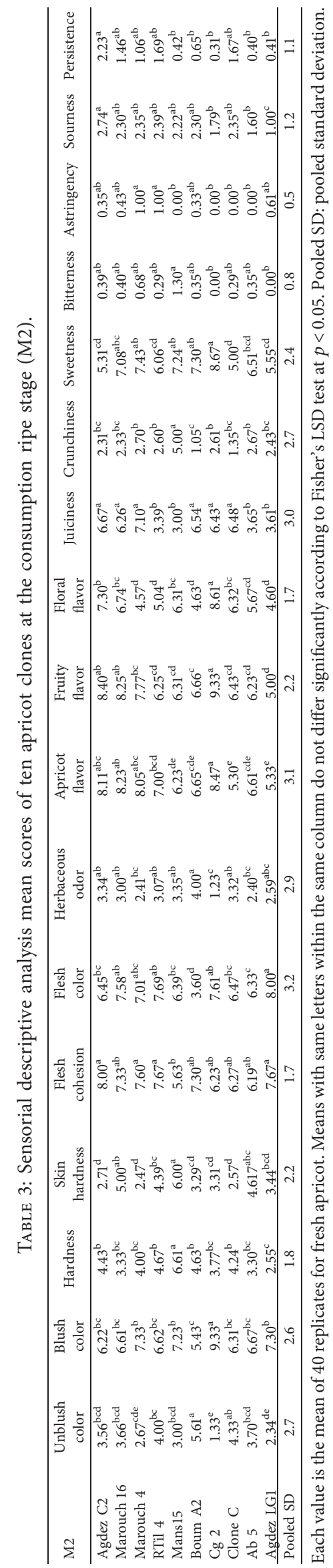




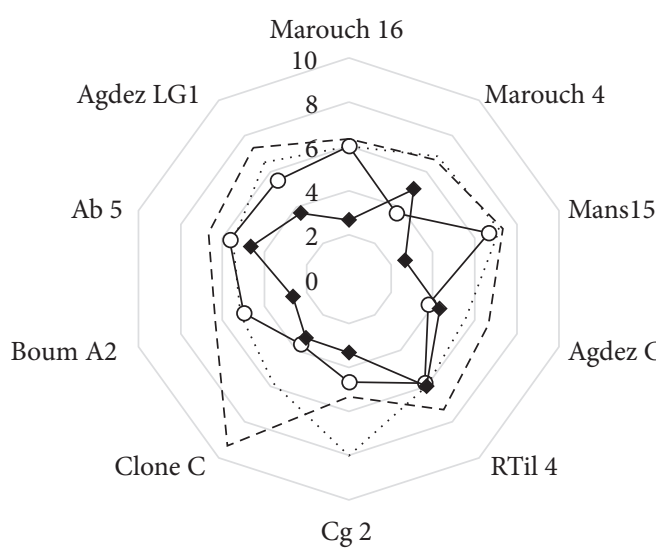

… M1-blush color
--- M2-blush color
$\multimap-$ M1-skin hardness
$\rightarrow-$ M2-skin hardness

(a)

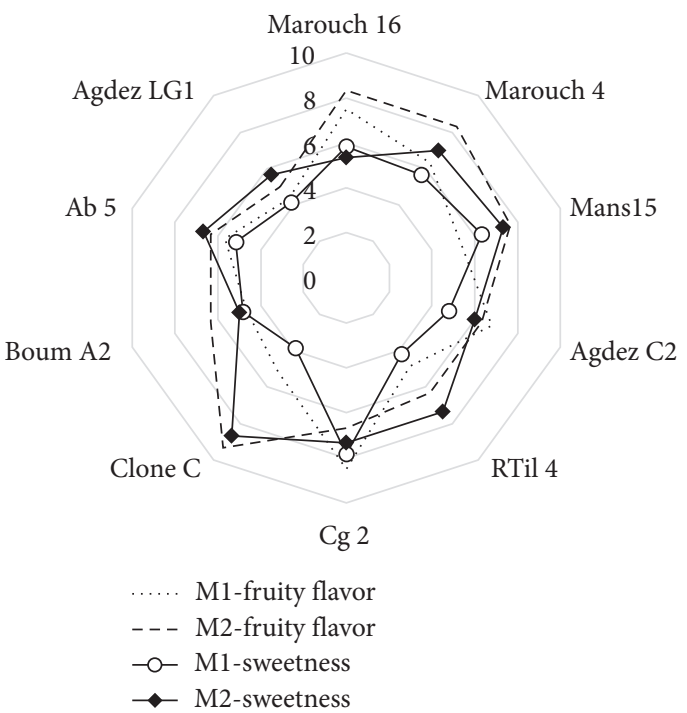

(b)

FIGURE 2: Main sensory attributes differentiating between clones at the commercial maturity (M1) and consumption (M2) stages.

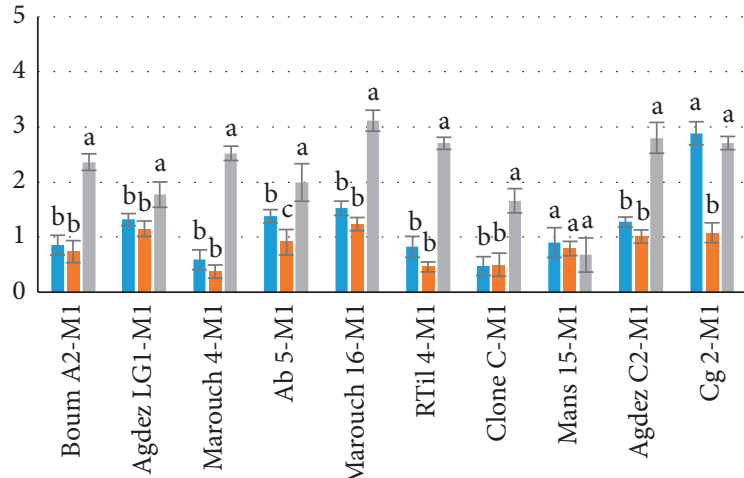

- Glucose

- Fructose

- Sucrose

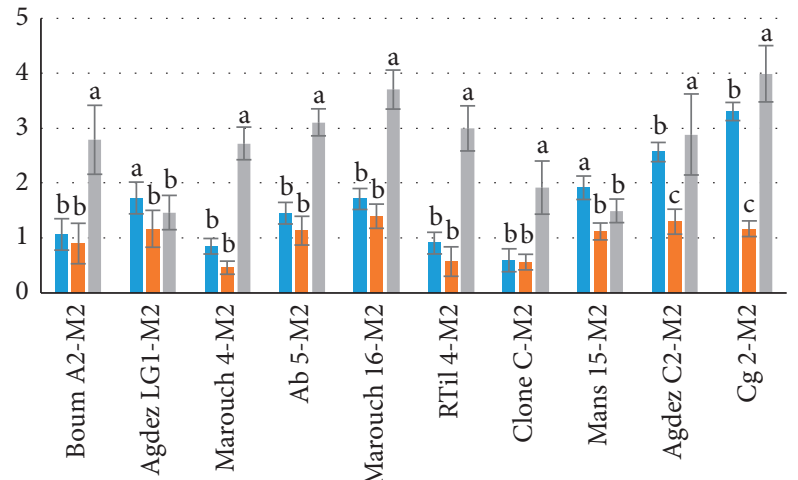

- Glucose

- Fructose

- Sucrose

(a)

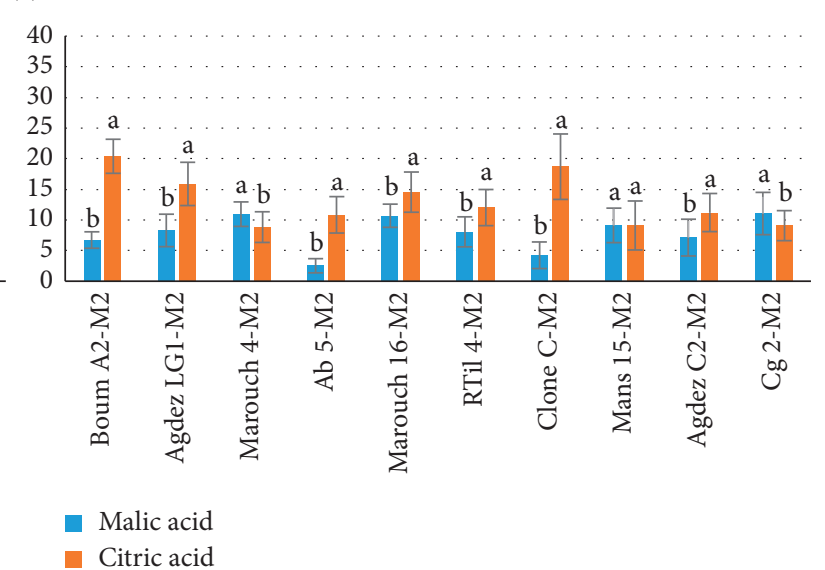

(b)

FIgURE 3: Soluble sugars and organic acid contents of ten apricot clones at commercial ripe (M1) and consumption ripe (M2) stages. The error bars represent the standard deviation of each replicate per maturity stage per clone. The means with same letters do not differ significantly according to Fisher's LSD test at $p<0.05$. (a) Sugars (g/100 g of fresh weight). (b) Organic acids (meq/100 g fresh weight). 
balanced fruit taste and attractive freshness; particularly, cultivars with high contents of citric acid are highly appreciated [37]. The taste can be described as comprised of five primary components: sweet, salty, sour, bitter, and umami [38]. Indeed, a balanced taste needed a balance between these five components whose organic acids content play a main role. Organic acids content helps to this balance as a function of $\mathrm{pH}$, as well as several factors associated with other acids such as concentration, total acidity, and quantity of undissociated acids. This shows that the organic acid content is important to keep the taste balance and any lack of acid influences the organoleptic quality of fruit [39]. DolencSturm et al. [12] have shown that, in sensory evaluations of fruits, sugars and organic acids, as well as their ratios, could be decisive in the quality of apricot taste.

In this study, citric acid was predominant for 8 apricot clones over 10 at the commercial stage (M2). For the ripest fruits, citric acid remains highly predominant for 4 clones ("Boum A2," "Clone C," “Agdez LG1," and "Ab 5"), malic acid being the major acid for red clones ("Mans 15" and "Cg 2") and "Marouch 4." The perception of citric acid was higher than that of malic acid. Containing three ionizable hydrogens per molecule, the citric acid is known for a bright, tart flavor that dissipates quickly with ripening. This acid pairs well with fruit flavors, especially citrus [40]. However, the malic acid is known for its smooth tartness and lingering sourness, works well with high intensity sweeteners, as its lingering sourness balances prolonged sweet tastes. Also, it is known for the ability to enhance fruit flavors [40].

For most studied clones, it is observed that the concentration of organic acids tends to decrease and the sugar content increases with maturity. However, these trends were weak compared with the study of Ayour et al. [22] and with other previous studies [28, 41]. Indeed, we observed a weak ripening effect on biochemical composition of apricots by comparing with the clone effect which was predominant especially on the organic acids $(p \leq 0.001)$.

3.3. Volatile Compounds. The volatile compounds identified in the studied apricot clones and their concentrations for commercial and consumption stages are listed in Tables 4 and 5, respectively. Twenty-five volatile compounds, including 10 aldehydes, 4 ketones, 7 alcohols, 4 acetates, and one acid, were identified. These classes were the most detected in previous studies on apricot fruits $[14,19,42]$. The major apricot volatile compounds identified in this study (hexanal, 2-hexenal, $\beta$-linalool, and 1-hexanol) were previously reported to be the major contributors to apricot aroma $[30,43]$, which include ethanol, hexanal, hexyl acetate, (Z)-3-hexenyl acetate, (E)-2-hexenyl acetate, 1-hexanol, (Z)-3-hexenol, and (E)-2-hexen-1-ol [44-47].

The volatile profiles indicated qualitative and quantitative differences $(p \leq 0.05)$ among clones but no specific relation with the ripening stage. Among these compounds, 10 compounds could contribute to discriminate apricot clones, namely, methyl acetate, ethanol, 1-penten-3-ol, 2hexen-1-ol acetate, 6-methyl-5-hepten-2-one, 1-hexanol, 2hexen-1-ol, $\beta$-linalool, $\beta$-cyclocitral, and $\beta$-ionone.
Highest concentrations were found for hexanal in both M1 and M2 stages. A previous study reported that hexanal and 2-hexenal are abundant in Turkish apricots where they are the major aldehydes. The concentration of hexanal in some of these cultivars varied from 28.4 to $1475.3 \mu \mathrm{g} / \mathrm{kg} \mathrm{FW}$ [19]. In another study [23], a concentration of $22.00 \mu \mathrm{g} / \mathrm{kg}$ FW was found for the same compound in apricot. The concentration of identified aldehydes in this study was considerably higher and depended strongly on the clone. For benzaldehyde, it has been reported as the main component of essential oil in Japanese apricots [46].

$\beta$-Linalool, 1-hexanol, and 2-hexen-1-ol were the most abundant alcohols (Table 4), which is in accordance with preceding studies $[19,23,44]$. It has been reported that alcohols vary from 123.10 to $938.20 \mu \mathrm{g} / \mathrm{kg}$ in apricot [19]. Other studies reported that among alcoholic structures including mainly six carbons, butanol [14], (Z)-3-Hexenol [47], (E)-2Hexen-1-ol [23, 47], linalool [14, 44, 47], and 1-hexanol [44], the compounds 1-hexanol, (Z)-3-hexenol, and (E)-2-hexen1-ol were present at high concentrations in all cultivars.

The ketones represent the third volatile compounds group. Among these ketones, 3-hydroxy-2-butanone was the most abundant. These results are in agreement with those reported by Ndomo et al. [48]; they have also reported that 3-hydroxy-2-butanone is responsible for the creamy flavor and used as a flavoring agent in some industrial preparation. However, in other previous studies $[14,19,44], \beta$-ionone and 6-methyl-5-hepten-2-one, which are also detected in this study, have been reported as the most dominant volatile components of fresh apricot. 6-Methyl-5-hepten-2-one and beta-ionone are characterized by the floral aroma [44]. Four acetate esters were found in low concentrations compared to the literature such as $853.10 \mu \mathrm{g} / \mathrm{kg}$ FW which was recorded in apricot by Gokbulut and Karabulut [19]. The most abundant ester was the methyl acetate, and it is one of the volatiles that discriminated the apricot clones. It has been described as contributors of the fruity characteristic according to the same authors [19].

Compared to the other classes of volatiles compounds, the acids group had the lowest abundance, which is in agreement with other studies $[19,48]$, and was only represented by acetic acid. Similar concentrations were reported [19]. Although, it was previously reported [45] that acetic acid was the most abundant among the 31 important volatile compounds of fresh apricots.

Based on volatiles quantification results, among all apricot clones, "Agdez C2," “Ab 5," "Cg 2," and "Mans 15” were determined with the highest concentration levels in both the maturity stages. However, compared to the literature, most studied apricot clones are rich in aromatic compounds according to their volatile compound contents at two different stages of maturity.

\subsection{Correlations between Sensory Perception and} Biochemical Traits. The comparison between sensory attributes, organic acids, and soluble sugars showed significant correlations. Two groups of sensory characteristics were identified: a first group of positively correlated attributes 


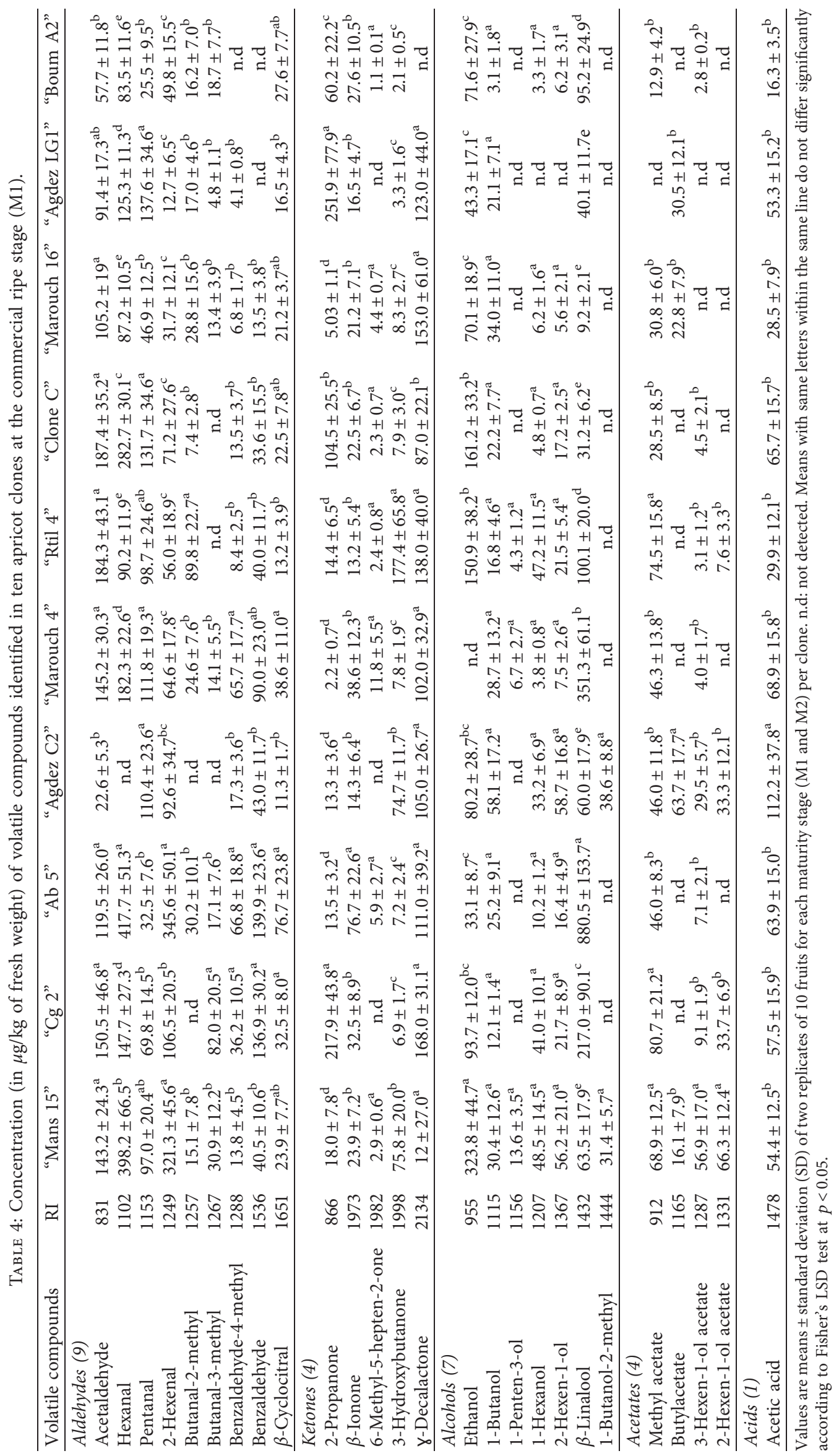




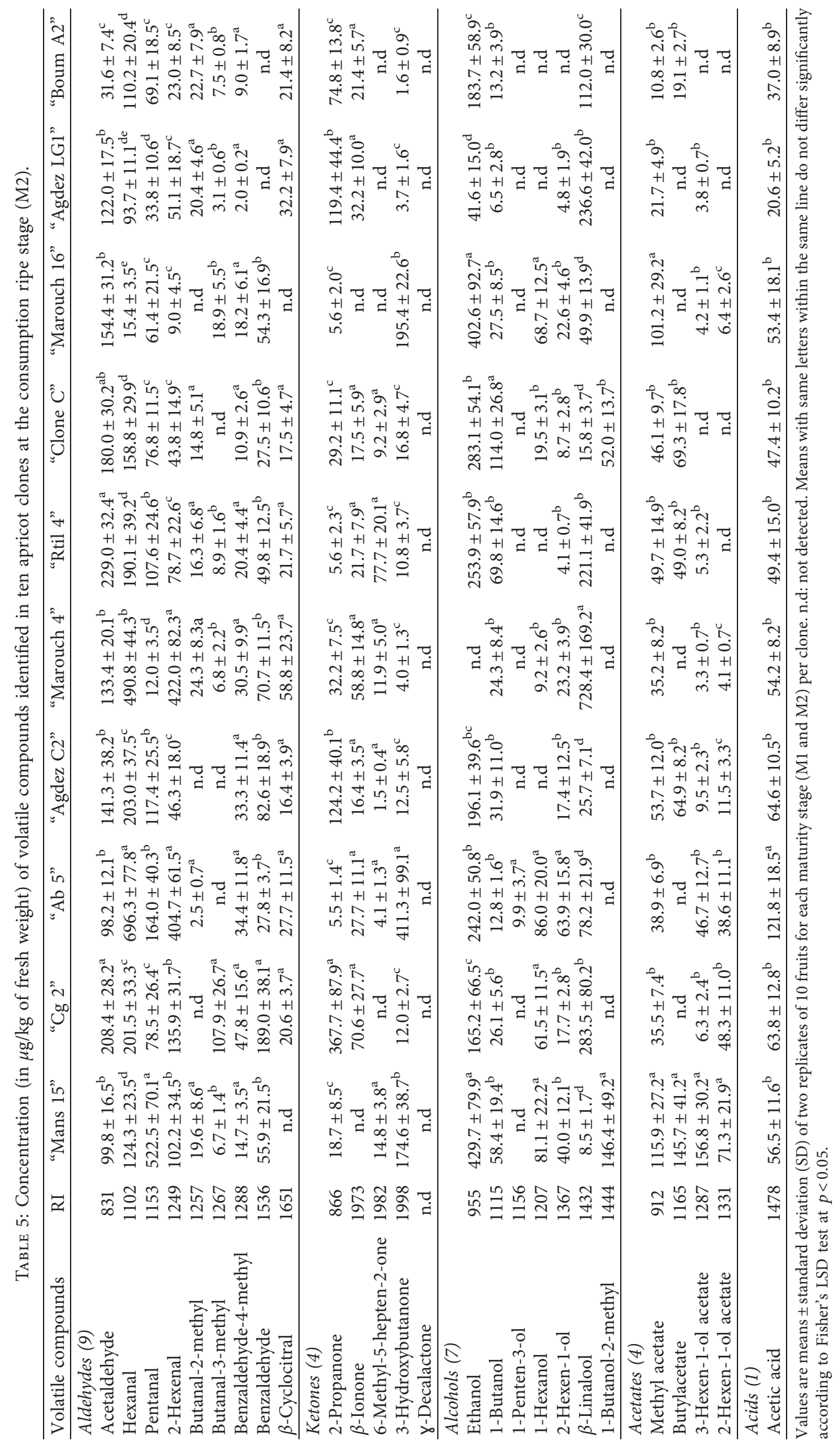


consisting of lightness, firmness, sourness, bitterness, astringency, herbaceous odor, crunchiness, and acidity persistence and a second group of correlated attributes constituted by blush color, sweetness, apricot flavor, fruity flavor, floral flavor, and juiciness. However, both the groups are negatively correlated.

In addition, good correlations appeared between some sensory attributes and the biochemical measurements, especially between color attributes and reducing sugars (glucose and fructose). The first group of attributes (named the sour group) was negatively correlated with glucose and fructose, positively correlated with citric acid, and vice versa for some attributes of group 2 (named sweet group) which were positively correlated with soluble sugars (glucose and fructose) and negatively with organic acids, especially citric acid. These results are consistent with a previous study which showed that perceptions of sugar and acidity interfered heavily in apricots. In fact, the more firm an apricot is, the more acidic it will be considered and slightly sweet, which depends on ripening and genotype impacts. It has also been shown that the perception of sweet taste depends not only on the soluble sugars content but also on acidity and firmness of apricot fruit [49]. Too much firmness is, therefore, inappropriate because consumers are primarily looking for sweetness, flavor, and fondant criteria [50]. This balanced relationship between the sugar and acid contents is very important on the quality of apricot fruits, as it was already reported in previous studies $[22,51,52]$. It made it possible to highlight all the sensory attributes and to discriminate apricots organoleptic quality.

In relation with the evolution of radars maps between the two maturity stages, a very strong effect of the ripening stage was observed noticed with the strongest correlations: positive between the three color attributes, the sweetness, and the juiciness and negative with the texture criteria (strongly correlated with each other). These correlations explain the processes of the loss of firmness and, therefore, the softening of the fruit, the degradation of chlorophylls, the accumulation of carotenes, and the increase of sugars during maturation. Moreover, the three tested flavors (apricot, fruity, and floral) were positively correlated with each other and negatively correlated with the herbaceous flavor, which is explained by the evolution of the aroma during the maturity.

Principal component analysis was performed between studied variables. The observed variability of $53.82 \%$ was explained by the first two principal components (F1 and F2) (Figure 4). F1 explains $31.74 \%$ of total variance, it opposed the sensory attributes that described the fruit in stage M1, namely, firmness, sourness, crispness, bitterness, astringency, unblush color, herbaceous odor, and malic and citric acids, from those that associated to stage M2, namely, sweetness, apricot, fruit and floral flavors, blush color, juiciness, and soluble sugars. The component F1, thus, highlights sensory attributes and volatiles associated to fruit maturity. Positive correlations (Figure 4(a)) were found between the sensory attributes of stage M2 and $\beta$-cyclocitral $(R=0.658), \quad \beta$-ionone $\quad(R=0.765), \quad$ butanal-3-methyl $(R=0.544)$, and acetaldehyde $(R=0.500)$. The attributes of the M1 stage were correlated with 2-hexenol $(R=0.507)$ and 1-hexanol $(R=0.495)$. A previous study reported that $\beta$-ionone significantly increases during fruit ripening correlated with sucrose and sweetness flavor, and it appears to be the key characteristic flavor factor contributing to consumer acceptance [53]. Moreover, $\beta$-ionone contributes to the flower and fruity notes of apricot, and it was reported negatively correlated with hexanal, which imparts green and grassy aromas and sourness [54]. The maturity stage affected the concentrations of aldehyde compounds (which decrease with ripening), especially the hexanal. The sample map (Figure 4(b)) discriminated the maturity stages along the F1 axis. At the M1 stage, apricots were firmer and acidic, characterized by herbaceous odor, and were rich in aldehydes and alcohols, especially 2 -hexenol and 1-hexanol. At stage M2, fruits were sweeter, rich in sugars, characterized by floral fruit and apricot flavors, and were correlated especially with $\beta$-ionone, $\beta$-cyclocitral, butanal-3-methyl, and acetaldehyde.

However, most volatile compounds were better discriminated by the $\mathrm{F} 2$, which opposed 2-hexenol $(R=0.777)$ and 1-hexanol $(R=0.830)$ to butanal-2-methyl $(R=-0.566)$ and benzaldehyde- 4 -methyl $(R=-0.515)$. In terms of samples, F2 was mostly defined by the clone Agdez C2 at the M1 stage, which had a volatile fingerprint different from all other apricots, with high acetic acid and acetate esters, pentanal, or 1-hexanol. Hexanal $(R=0.647), 2$-hexenal $(R=0.763), 2$ hexenol acetate $(R=0.528)$, and benzaldehyde $(R=0.512)$ were better represented on the F3 (data not shown).

The apricot samples were harvested at different time intervals depending on the degree of ripening (M1: commercial and M2: consumption). In fact, the factorial representation of the sensory profile depends to the concentrations of volatile compounds whish also depend on a series of physical and biochemical changes during maturation [19]. Nevertheless, an impact of the genotype seems so important, such as the volatile compositions of apricot cultivars growing under the same conditions turned out to be considerably different. The differentiations in volatile compositions and sensory profiles of apricot fruits were also reported in data from previous studies [14, 19, 44, 47].

Regarding apricot clones, the orange (especially "Ab 5," "Marouch 4," and "Marouch 16") and the red ones ("Mans 15 ," "Cg 2") are most rich in volatile compounds in both maturity stages. "Ab 5" was rich in apricot flavors and characterized with a balance of volatile compounds (qualitatively and quantitatively). "Cg 2" is characterized by a good acid-sugar balance regarding its composition in soluble sugars and organic acids. Also, "Cg 2" represents the genotype least affected by maturation, and this shows a sensory quality of this clone that could be the issue of fruit valuation for a longer maturation period of apricots.

Gokbulut and Karabulut [19] also reported that the apricot sensory profile depends on a series of physical and biochemical changes during maturation. The differentiations in aroma composition and sensory profiles of apricot genotypes fruits were also reported previously [19, 44, 47]. Regarding apricot clones, the red apricots, especially "Cg 2" and orange ones (especially "Ab 5" and "Marouch 16"), were characterized by 


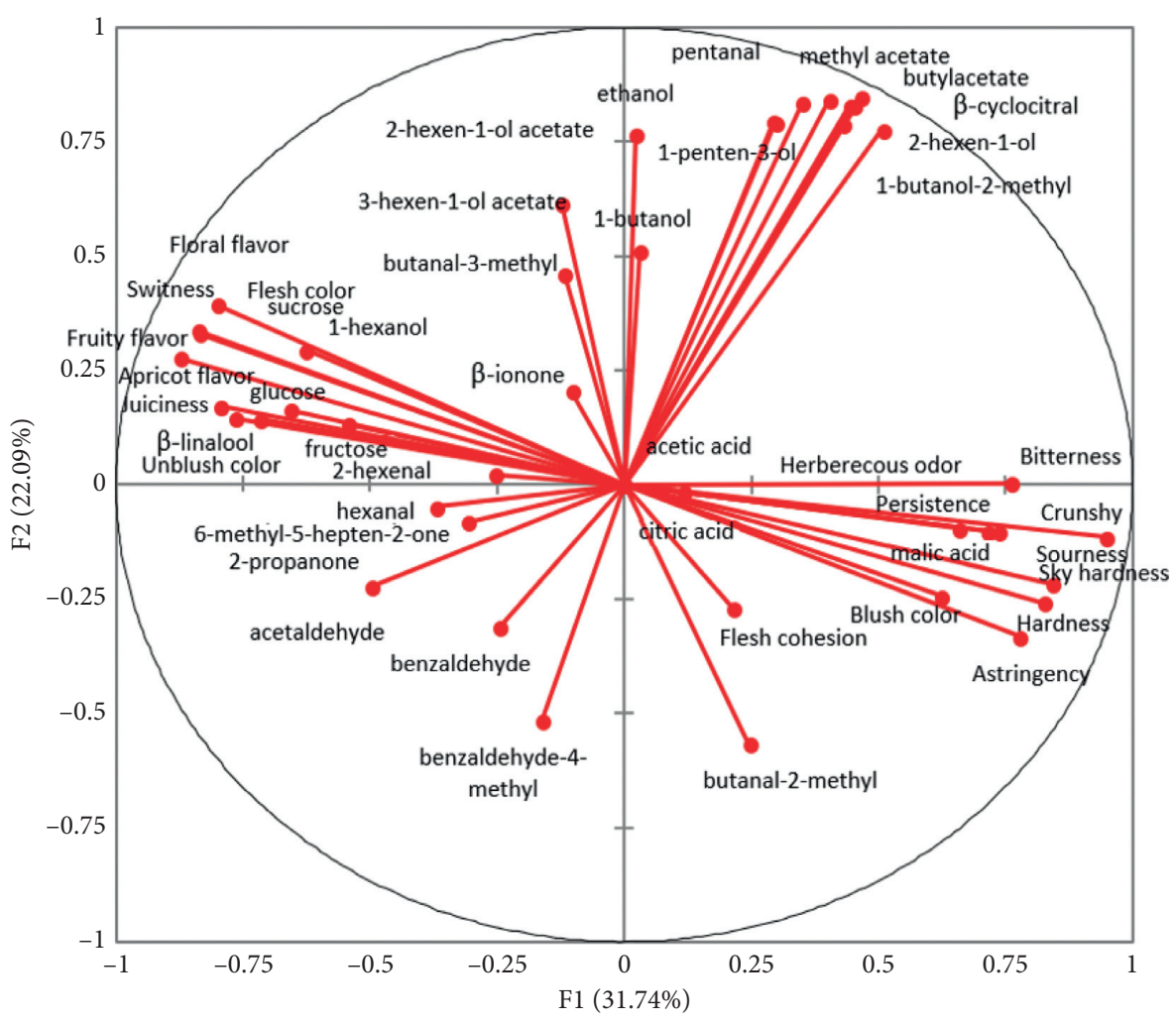

(a)

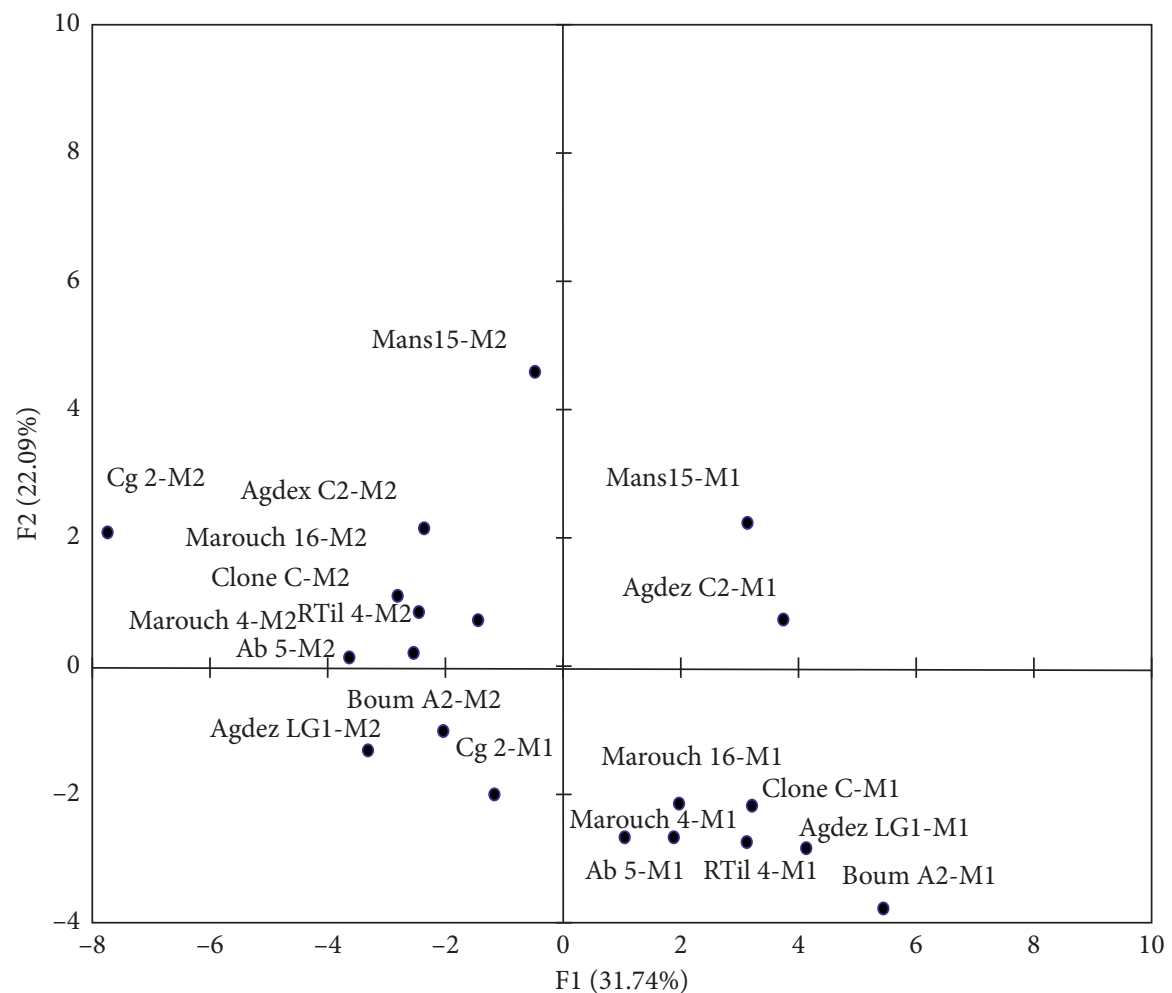

(b)

Figure 4: Principal component analysis (PCA) of volatile compounds and the sensory profile of apricot clones. (a) Correlation circle of sensory attributes, soluble sugars, organic acids, and volatile compounds. (b) Segregation of the apricot clones based on the studied parameters depending on maturity stages (M1: commercial ripe; M2: consumption ripe). 
good organoleptic quality, with "Cg 2" as the most floral one. "Ab 5," "Marouch 4," "Agdez C2," and "Rtil 4" were characterized with good sensory attributes for the M2 stage and were rich in apricot flavors. Moreover, "Cg 2" was characterized by a good acid-sugar balance regarding its composition in soluble sugars and organic acids in both maturity stages. It represents the genotype least affected by maturation. This shows a sensory quality of this clone that could be a subject of fruit valuation for a longer maturation period. Gokbulut and Karabulut [19] also reported that the apricot sensory profile depends on a series of physical and biochemical changes during maturation. The differentiations in aroma composition and sensory profiles of apricot genotypes fruits were also reported previously [19, 44, 47]. Regarding apricot clones, the red apricots, especially "Cg 2" and orange ones (especially "Ab 5" and "Marouch 16"), were characterized by good organoleptic quality, with "Cg 2" as the most floral one. "Ab 5," "Marouch 4," "Agdez C2," and "Rtil 4" were characterized with good sensory attributes for the M2 stage and were rich in apricot flavors. Moreover, "Cg 2" was characterized by a good acidsugar balance regarding its composition in soluble sugars and organic acids in both maturity stages. It represents the genotype least affected by maturation. This shows a sensory quality of this clone that could be a subject of fruit valuation for a longer maturation period.

\section{Conclusions}

For a tasty fruit like apricot, quality is defined by the perception of several criteria broken down and dissected using sensory and biochemical indicators. The ten studied Moroccan clones have very promising and interesting sugars and organic acids contents and sensory profiles, leading to reasonably good overall fruit quality. This study also highlighted that soluble sugars and organic acids are important biochemical parameters for the sensory perception of apricot fruit. The principal component analysis revealed that the maturity stage has a significant impact in determining the perception of sensory quality related to biochemical parameters. Red apricots were among the recommended cultivars for the cultivation and for apricots consumption as fruits, especially "Cg 2" which was considered the most flavorful and aromatic clone, followed by "Marouch 4," "Agdez C2," "Mans 15," “Ab 5," and "Rtil 4" which were characterized with good sensory attributes at the consumption stage (M2). In addition, all clones were characterized in this study by very interesting sensory attributes and sugar-acid balances expressing a good overall quality of the fruits. The excellent quality properties of these clones, as well as the criteria associated with the ripening stages, certainly represent valuable genetic characteristics for extending the harvesting season of good quality apricots in Morocco and in all Mediterranean regions.

\section{Data Availability}

The data (experiences, analyses, and results) used to support the findings of this study are included within the article and in other published articles. A prior study was cited at relevant places within the text as reference [22], and other articles are available at https://www.researchgate.net/ scientific-contributions/2110738085_Jamal_Ayour.

\section{Conflicts of Interest}

The authors declare that there are no conflicts of interest regarding the publication of this paper.

\section{Acknowledgments}

The authors are grateful to the technical staff of the INRA SQPOV Research Unit (Avignon, France) and the INRA Laboratory of Agri-Food Technology and Quality and of the INRA Saâda Experimental Field (Marrakesh, Morocco) and to the INRA Fruits Sensory Panel (Marrakesh, Morocco) for their precious collaboration in the development of this work. This research was performed as part of the research activities of the Regional Center for Agricultural Research in Marrakesh belonging to the National Institute for Agricultural Research (INRA Morocco). It was also supported by the grant of the Moroccan Ministry of National Education, Professional Training, Higher Education, and Scientific Research attributed to author Jamal Ayour in the framework of the doctoral studies.

\section{Supplementary Materials}

Supplementary TABLE 1: morphological characteristics of the studied ten apricot clones. (Supplementary Materials)

\section{References}

[1] D. Bassi, F. Bartolozzi, and E. Muzzi, "Patterns and heritability of carboxylic acids and soluble sugars in fruits of apricot (Prunus armeniaca L.)," Plant Breeding, vol. 115, no. 1, pp. 67-70, 1996.

[2] D. Bassi and R. Selli, "Evaluation of fruit quality in peach and apricot," Advances in Horticultural Science, vol. 4, no. 2, pp. 107-112, 1990.

[3] F. Gurrieri, J. M. Audergon, G. Albagnac, and M. Reich, "Soluble sugars and carboxylic acids in ripe apricot fruit as parameters for distinguishing different cultivars. Use of principal component analysis to characterize apricot fruit quality," Euphytica, vol. 117, pp. 183-189, 2001.

[4] N. Lespinasse, J. Lichou, and M. Jay, "Sensory evaluation on apricot: descriptive analysis," Acta Horticulturae, vol. 701, pp. 595-598, 2006.

[5] S. Lurol, C. Hilaire, J. Lichou, and M. Jay, Pêche-Abricot de la Récolte au Conditionnement: Outils Pratiques, Ctifl, Paris, France, 2007.

[6] C. Aubert, Z. Günata, C. Ambid, and R. Baumes, "Changes in physicochemical characteristics and volatile constituents of yellow- and white-fleshed nectarines during maturation and artificial ripening," Journal of Agricultural and Food Chemistry, vol. 51, no. 10, pp. 3083-3091, 2003.

[7] C. H. Bailey and L. F. Hough, "Apricots," "Apricots," in Advances in Fruit Breeding, J. Janick and J. N. Moore, Eds., pp. 367-384, Purdue University Press, West Lafayette, Indiana, 1975.

[8] H. Valdés, M. Pizarro, R. Campos-Vargas, R. Infante, and B. G. Defilippi, "Effect of ethylene inhibitors on quality 
attributes of apricot cv. Modesto and Patterson during storage," Chilean Journal of Agricultural Research, vol. 69, no. 2, pp. 134-144, 2009.

[9] E. Mratinić, B. Popovski, T. Milošević, and M. Popovska, "Evaluation of apricot fruit quality and correlations between physical and chemical attributes," Czech Journal of Food Sciences, vol. 29, no. 2, pp. 161-170, 2011.

[10] I. J. Hormaza, H. Yamane, and J. Rodrigo, "Apricot,"“Apricot," in Genome Mapping and Molecular Breeding in Plants, C. Kole, Ed., vol. 4Springer Verlag, Fruits and Nuts, , pp. 171-187, Springer Verlag, 2007.

[11] S. Ishag, A. H. Rathore, S. Majeed, S. Awan, and Z. S. Ali Shan, "The studies on the physico-chemical and organoleptic characteristics of apricot (Prunus armeniaca L.) produced in Rawalakot, Azad Jammu and Kashmir during storage," Pakistan Journal of Nutrition, vol. 8, no. 6, pp. 856-860, 2009.

[12] K. Dolenc-Sturm, F. Stampar, and V. Usenik, "Evaluating of some quality parameters of different apricot cultivars using HPLC method," Acta Alimentaria, vol. 28, no. 4, pp. 297-309, 1999.

[13] D. Ruiz and J. Egea, "Phenotypic diversity and relationships of fruit quality traits in apricot (Prunus armeniaca L.) germplasm," Euphytica, vol. 163, no. 1, pp. 143-158, 2007.

[14] H. Solís-Solís, M. Calderón-Santoyo, S. Schorr-Galindo, G. Luna-Solano, and J. Ragazzo-Sánchez, "Characterization of aroma potential of apricot varieties using different extraction techniques," Food Chemistry, vol. 105, no. 2, pp. 829-837, 2007.

[15] R. Azodanlou, C. Darbellay, J.-L. Luisier, J.-C. Villettaz, and R. Amadò, "Development of a model for quality assessment of tomatoes and apricots," LWT-Food Science and Technology, vol. 36, no. 2, pp. 223-233, 2003.

[16] R. Botondi, D. DeSantis, A. Bellincontro, K. Vizovitis, and F. Mencarelli, "Influence of ethylene inhibition by 1-methylcyclopropene on apricot quality, volatile production, and glycosidase activity of low- and high-aroma varieties of apricots," Journal of Agricultural and Food Chemistry, vol. 51, no. 5, pp. 1189-1200, 2003.

[17] G. Reineccius and H. B. Heath, Flavor Chemistry and Technology, CRC Press Taylor \& Francis Group, Boca Raton, FL, USA, 2nd edition, 2009.

[18] C. Aubert, P. Bony, G. Chalot, and V. Hero, "Changes in physicochemical characteristics and volatile compounds of apricot (Prunus armeniaca L. cv. Bergeron) during storage and post-harvest maturation," Food Chemistry, vol. 119, no. 4, pp. 1386-1398, 2010.

[19] I. Gokbulut and I. Karabulut, "SPME-GC-MS detection of volatile compounds in apricot varieties," Food Chemistry, vol. 132, no. 2, pp. 1098-1102, 2012.

[20] P. D. Drogoudi, S. Vemmos, G. Pantelidis, E. Petri, C. Tzoutzoukou, and I. Karayiannis, "Physical characters and antioxidant, sugar, and mineral nutrient contents in fruit from 29 apricot (Prunus armeniaca L.) cultivars and hybrids," Journal of Agricultural and Food Chemistry, vol. 56, no. 22, pp. 10754-10760, 2008.

[21] H. Bae, S. K. Yun, I. K. Yoon, E. Y. Nam, J. H. Kwon, and J. H. Jun, "Assessment of organic acid and sugar composition in apricot plum-cot, plum, and peach during fruit development," Journal of Applied Botany and Food Quality, vol. 87, pp. 24-29, 2014.

[22] J. Ayour, M. Sagar, H. Harrak et al., "Evolution of some fruit quality criteria during ripening of twelve new Moroccan apricot clones (Prunus armeniaca L.)," Scientia Horticulturae, vol. 215, pp. 72-79, 2017.
[23] E. Gómez and C. A. Ledbetter, "Development of volatile compounds during fruit maturation: characterization of apricot and plum-apricot hybrids," Journal of the Science of Food and Agriculture, vol. 74, no. 4, pp. 541-546, 1997.

[24] H. J. D. Lalel, Z. Singh, and S. C. Tan, "Aroma volatiles production during fruit ripening of "Kensington Pride" mango," Postharvest Biology and Technology, vol. 27, no. 3, pp. 323-336, 2003.

[25] D. Ruiz and J. Egea, "Analysis of the variability and correlations of floral biology factors affecting fruit set in apricot in a mediterranean climate," Scientia Horticulturae, vol. 115, no. 2, pp. 154-163, 2008.

[26] I. Urdapilleta, N. C. Ton, C. Saint-Denis, and F. Huon de Kermadec, Traité D'évaluation Sensorielle. Aspects Cognitifs et Métrologiques des Perceptions, Dunod, Paris, France, 2001.

[27] D. Christen, J. Rossier, C. Evéquoz, G. Nicollier, J. Rey-Siggen, and L. Morin-Audebrand, "Analyses sensorielles de variétés d'abricots," Revue Suisse Viticulture, Arboriculture, Horticulture, vol. 43, no. 3, pp. 152-159, 2011.

[28] P. Melgarejo, Á. Calín-Sánchez, Á. A. Carbonell-Barrachina et al., "Antioxidant activity, volatile composition and sensory profile of four new very-early apricots (Prunus armeniaca L.)," Journal of the Science of Food and Agriculture, vol. 94, no. 1, pp. 85-94, 2014.

[29] C. Le Bourvellec, B. Gouble, S. Bureau et al., "Impact of canning and storage on apricot carotenoids and polyphenols," Food Chemistry, vol. 240, pp. 615-625, 2018.

[30] C. Aubert and C. Chanforan, "Postharvest changes in physicochemical properties and volatile constituents of apricot (Prunus armeniaca L.). Characterization of 28 cultivars," Journal of Agricultural and Food Chemistry, vol. 55, no. 8, pp. 3074-3082, 2007.

[31] S. Bureau, D. Ruiz, M. Reich et al., "Application of ATR-FTIR for a rapid and simultaneous determination of sugars and organic acids in apricot fruit," Food Chemistry, vol. 115, no. 3, pp. 1133-1140, 2009.

[32] V. Schmitzer, A. Slatnar, M. Mikulic-Petkovsek, R. Veberic, B. Krska, and F. Stampar, "Comparative study of primary and secondary metabolites in apricot (Prunus armeniaca L.) cultivars," Journal of the Science of Food and Agriculture, vol. 91, no. 5, pp. 860-866, 2010.

[33] O. Caliskan, S. Bayazit, and A. Sumbul, "Fruit quality and phytochemical attributes of some apricot (Prunus armeniaca L.) cultivars as affected by genotypes and seasons," Notulae Botanicae Horti Agrobotanici Cluj-Napoca, vol. 40, no. 2, pp. 284-294, 2012.

[34] G. Campo, I. Berregi, R. Caracena, and J. I. Santos, "Quantitative analysis of malic and citric acids in fruit juices using proton nuclear magnetic resonance spectroscopy," Analytica Chimica Acta, vol. 556, no. 2, pp. 462-468, 2006.

[35] E. B. Akin, I. Karabulut, and A. Topcu, "Some compositional properties of main Malatya apricot (Prunus armeniaca L.) varieties," Food Chemistry, vol. 107, no. 2, pp. 939-948, 2008.

[36] G. Durmaz, M. Çam, T. Kutlu, and Y. Hişil, "Some physical and chemical changes during fruit development of five common apricot (Prunus armeniaca L.) cultivars," Food Science and Technology Research, vol. 16, no. 1, pp. 71-78, 2010.

[37] F. Štampar, V. Usenik, and K. Dolenc-Šturm, "Evaluating of some quality parameters of different apricot cultivars using HPLC method," Acta Alimentaria, vol. 28, no. 4, pp. 297-309, 1999.

[38] D. M. Barrett, J. C. Beaulieu, and R. Shewfelt, "Color, flavor, texture, and nutritional quality of fresh-cut fruits and 
vegetables: desirable levels, instrumental and sensory measurement, and the effects of processing," Critical Reviews in Food Science and Nutrition, vol. 50, no. 5, pp. 369-389, 2010.

[39] E. R. D. C. Neta, S. D. Johanningsmeier, and R. F. Mcfeeters, "The chemistry and physiology of sour taste-a review," Journal of Food Science, vol. 72, no. 2, pp. 33-38, 2007.

[40] K. L. Penniston, S. Y. Nakada, R. P. Holmes, and D. G. Assimos, "Quantitative assessment of citric acid in lemon juice, lime juice, and commercially-available fruit juice products," Journal of Endourology, vol. 22, no. 3, pp. 567-570, 2009.

[41] J. Goliáš, J. Letal, and L. Dokoupil, "Influence of maturity on volatile production and chemical composition of fruits of six apricot cultivars," Journal of Applied Botany and Food Quality, vol. 84, no. 1, pp. 76-84, 2011.

[42] R. L. Bianco, V. Farina, S. G. Indelicato, F. Filizzola, and P. Agozzino, "Fruit physical, chemical and aromatic attributes of early, intermediate and late apricot cultivars," Journal of the Science of Food and Agriculture, vol. 90, no. 6, pp. 1008-1019, 2010.

[43] M. González-Agüero, S. Troncoso, O. Gudenschwager, R. Campos-Vargas, M. A. Moya-León, and B. G. Defilippi, "Differential expression levels of aroma-related genes during ripening of apricot (Prunus armeniaca L.)," Plant Physiology and Biochemistry, vol. 47, no. 5, pp. 435-440, 2009.

[44] S. Guillot, L. Peytavi, S. Bureau et al., "Aroma characterization of various apricot varieties using headspace-solid phase microextraction combined with gas chromatography-mass spectrometry and gas chromatography-olfactometry," Food Chemistry, vol. 96, no. 1, pp. 147-155, 2006.

[45] V. Greger and P. Schieberle, "Characterization of the key aroma compounds in apricots (Prunus armeniaca) by application of the molecular sensory science concept," Journal of Agricultural and Food Chemistry, vol. 55, no. 13, pp. 52215228, 2007.

[46] M. Miyazawa, N. Shirakawa, H. Utsunomiya, K.-i. Inada, and T. Yamada, "Comparision of the volatile components of unripe and ripe Japanese apricot (Prunus mume Sieb. et Zucc.)," Natural Product Research, vol. 23, no. 17, pp. 1567-1571, 2009.

[47] G. R. Takeoka, R. A. Flath, T. R. Mon, R. Teranishi, and M. Guentert, "Volatile constituents of apricot (Prunus armeniaca)," Journal of Agricultural and Food Chemistry, vol. 38, no. 2, pp. 471-477, 1990.

[48] A. F. Ndomo, B. Weissbecker, and S. Schütz, "Olfactory responses of Plodia interpunctella (Hubner, 1813) (Lepidoptera: Pyralidae) to dried apricot volatiles,"' Olfactory responses of Plodia interpunctella (Hubner, 1813) (Lepidoptera: Pyralidae) to dried apricot volatiles," in Proceedings of the 9th International Conference on Controlled Atmosphere and Fumigation in Stored Products, S. Navarro, H. J. Banks, D. S. Jayas et al., Eds., ARBER Professional Congress Services, Antalya, Turkey, pp. 728-733, October 2012.

[49] M. Jay, N. Lancelin, and J. Lichou, "Filière analyses sensorielles: la perception des abricots par les dégustateurs, arboriculture fruitière," Revue Suisse Viticulture, Arboriculture, Horticulture, vol. 549, no. 3, pp. 41-43, 2011.

[50] D. Scandella, I. Sibille, S. Vénien, J. Lichou, and M. Jay, "Abricot: évaluation des atouts organoleptiques," Infos-Ctifl, vol. 141, pp. 22-25, 1998.

[51] J. Stanley, J. Feng, and S. Olsson, "Crop load and harvest maturity effects on consumer preferences for apricots," Journal of the Science of Food and Agriculture, vol. 95, no. 4, pp. 752-763, 2015.
[52] K. Robini, L. Hashim, D. Ladeveze et al., "Prediction of sensory data by instrument measurements of representative apricot (Prunus armeniaca L.) cultivars," Acta Horticulturae, vol. 701, pp. 533-540, 2006.

[53] W. Xi, H. Zheng, Q. Zhang, and W. Li, "Profiling taste and aroma compound metabolism during apricot fruit development and ripening," International Journal of Molecular Sciences, vol. 17, no. 7, p. 998, 2016.

[54] E. Gatti, B. G. Defilippi, S. Predieri, and R. Infante, "Apricot (Prunus armeniaca L.) quality and breeding perspectives," Journal of Food Agriculture and Environment, vol. 7, no. 3, pp. 573-580, 2009. 